\title{
Research on the Information Management in Constructional Organization Design of Single Built Civil Air Defense based on Geographic Information System
}

\author{
Zhangyin Lin* \\ Urban Construction Department, Shaoyang University, Hunan Province, China \\ *15573902000@163.com
}

\begin{abstract}
With the rapid development of urbanization, the importance of civil air defenses projects is becoming more and more obvious, how to use the new technology to carry on the effective management becomes an important issue. In this paper, the author research on constructional organization design of single built civil air defense based on geographic information system. By using the technology of CIS and MIS to manage the attribute data and spatial geographic data of civil air dejense project, enterprise could manage the civil air defense engineering efficiently. In addition, as the GIS function is added to the system, civil air defense project location can be directly displayed on the map, all the operations of the system can be directly carried out on the map interface, making the system more easy to use than the traditional MISCyytem.
\end{abstract}

Keywords: Geographic Information-System, Engineering survey, Civil air defense project, Constructional Organization

\section{Introduction}

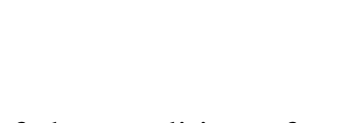

With the enhancement of the condition of modern high tech war air crackdown, as wartime covert personnel and supplies arr defense projects, usually used for important engineering and economic construction, its importance is more and more obvious[1]. In China, city and the rapid development of the civil air defense engineering combined the guidelines for the managemen of civil air defense engineering has brought many problems as how to adop hew technology, effective management and use of civil air defense engineering is an important issue of practical significance[2-3]. Based on the object-oriented conep theory and design method, using MIS and GIS integration technology, the design and implementation of civil air defense engineering information management sŷstem based on GIS[4]. The system uses MaP0bjeCtS as the development of geographic information system based on the data management module, Oracle powerfuldatabase on the object-oriented design and implementation of a series of air defense based on data structure and the realization of the civil air defense engineering electronic map information input, based on a series of functions such as editing, to image based on electronic map, effectively the expected effect of civil air defense engineering information management; in addition, with the help of GIS geographic spatial data management and spatial analysis ability[5-7]. In the management of the project attribute data of Oracle database based on sound analysis and evaluation of the overall situation of implementation of selected regional air defense projects, single air defense projects within a certain distance of subtle analysis of regional population and the hidden population all entered the civil air defense engineering works required time analysis and other important analysis function, it achieves good results[8].

Civil air defense project information management is also facing an increasingly difficult task, civil air defense projects if the management is not good, it is difficult to 
play the role of the application, but will cause some social problems. On the one hand, the expansion of urban construction and the transformation of old urban areas, resulting in the emergence of a large number of new civil air defense projects and the original civil air defense projects demolition, abandoned, civil air defense project information needs to be updated in a timely manner[9]. On the other hand, because of that the development of urban commercial activities most in busy urban civil air defense project is usually used as a commercial or civil, some large air defense projects usually are used as underground shopping malls and other commercial purposes, air defense underground space of some big cities is migrant workers used to rent. Managers not only to timely registration is used as the use of civil air defense projects, the use of area and the legal representative and other information, while also increasing the use of engineering management and supervision, to avoid the occurrence of safety accidents. Therefore, the task of civil air defense project information management is very heavy, it is difficult to use the traditional management methods to achieve the desired results. In the civil air defense project information management, the current management situation in our country is stît mainly based on paper file management, management method is backward, the management efficiency is low[10]. A few developed areas just realized from the transfornation of paper archives management to the database information management, developed some MIS system for information management of civil air defense engineering, such as the Civil Air Defense Office of Nanjing City completed the Nanjing/city within the jurisdiction of the civil air defence engineering information mangement system, to achieve the multiple functions of the storage, management, query, statistics, report generation and printing, good results have been achieved. However, the integration technology of GIS and MIS of civil air defense projects of attribute data and spatial geographical data at the same time management, efficient management of civil air defense engineering information, and to carry out the necessary functional analysis system so far has not been achieved. The establishment of civil air defense engineering management information system based on Component GIS civil air defense engineering information stored in the database, in the interface of visual information query, add, modify, delete and other operations becomes very simple, which will greatly improve the efficiency of information management of civil air defense engineering. At the same time, the database technology also helps to enhance the security of information. Also because of the GIS functions into the system, the position of the civil air defense engineering can intuitively display on the map, all operations of the system can be in the map interface intuitively, enables the system to use than the traditional MIS system more simple and easy to use.

\section{Geographic Information System Related Theory}

\subsection{Geographic Information System}

Geographic information system is described in the collection, storage, management, analysis information system data on the surface of the earth and space and geographical distribution. It is based on geo spatial database in computer software, hardware environment, relevant data were collected, the space management, operation, analysis, simulation and display, and use of geographic model analysis method, to provide spatial and dynamic geographical information, geographical research, evaluation, management, a kind of computer application system for quantitative analysis and decision service set up. The development of geographic information system began in 1960s, after decades of development, has made remarkable achievements, widely used in resource investigation, environmental assessment, regional development planning, public facilities management, traffic safety and other fields, has become an interdisciplinary research field.

On the one hand, the geographic information system (GIS) is a discipline, is to describe, storage, analysis and output the spatial information of the theory and method of 
a new cross subject; on the other hand, geographic information system (GIS) is a technical system, is based on geo spatial database based on the geographical model analysis method, the timely provision of a variety of spatial and dynamic geographic information, geographic research and decision service system in computer technology. Therefore, geographical information system should has the characteristics of the following three aspects:

1. Has the ability to collect, manage, analyze and export a variety of geographic information, and has the characteristics of space and dynamic;

2. Spatial geographic data management is supported by the computer system, which is simulated by a computer program or a special geographical analysis method, which is useful for the spatial data, and generates useful information;

3. The support of computer system is an important feature of the geographic information system, so the geographic information system can be fast, accurate, comprehensive and complex geographic system for spatial location and process dynamic analysis.

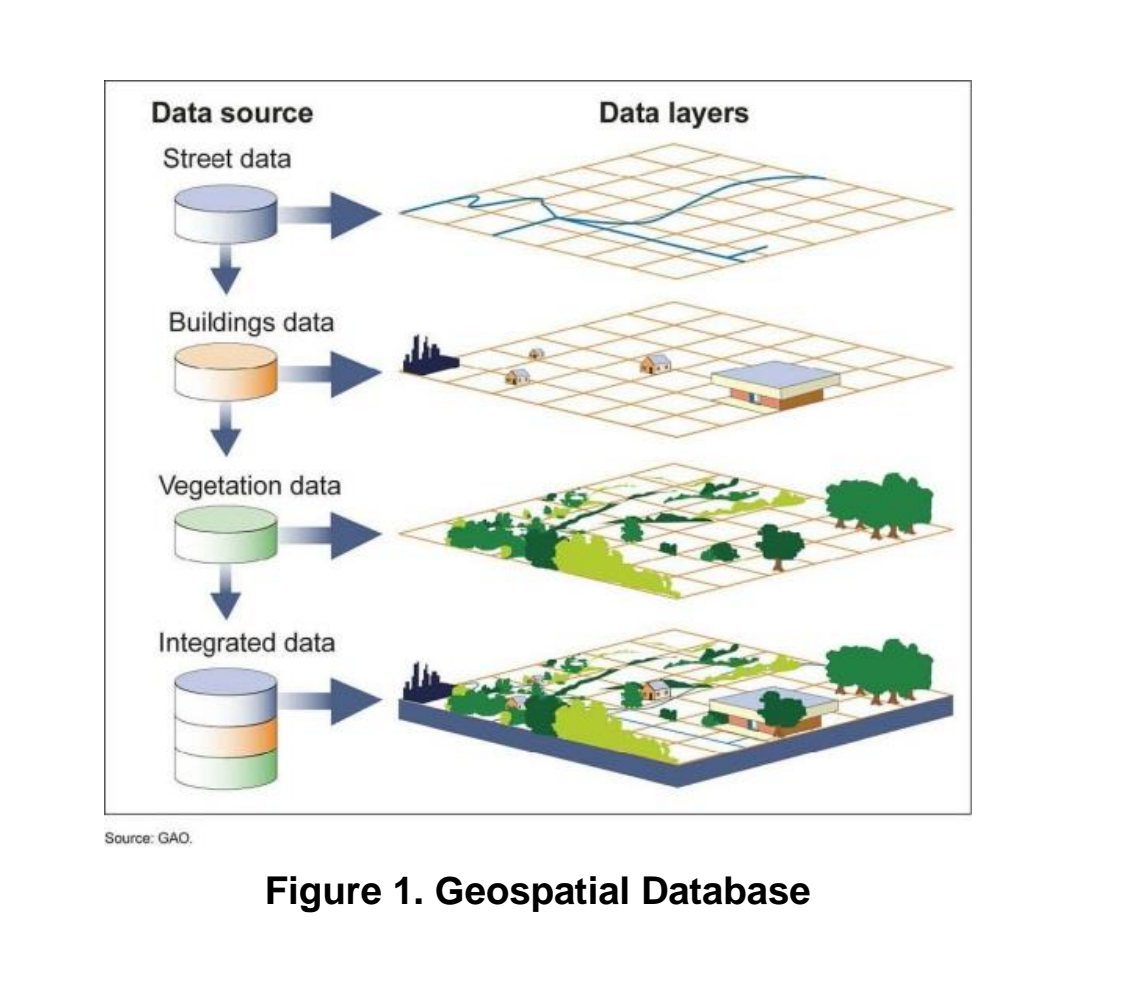

\subsection{Componen Type GIS}

After several decades of development, although the traditional GIS in function has been more mature, but because of these systems are based on more than and 10 years ago, the spftware technology development, is an independent closed system. At the same time, GiS software has become increasingly large, difficult for users to master, expensive, hindering the popularization and application of GIS. With the development of component technology, GIS software like other software, revolutionary changes have taken place, namely from the past manufacturers provides system or with secondary development function of the software, the transition to the components provided by the users themselves to develop in the direction of up, the components of the secondary development of GIS. Component GIS appear which provides a new method for the traditional GIS faces a variety of problems. Component Gls development platform is usually designed to be three level structure: 
Basic components: at the lowest level of the platform, is the basis of the entire system, mainly for spatial data management, provides the basic interaction process and can be a flexible way to connect with the database system.

Senior General Assembly: senior general component is constructed by basic components, for generic function, simplify the development of the user, as shown tool components, component selection tool, editing tool assembly, property browser component, and so on. Between them the collaborative control messages are encapsulated. The component level after the package, the secondary development is more simple. As an edit query system, if the development of the basic platform, you need to write a lot of code, and the use of advanced general assembly, only a few words of program is enough the.

Industry components: industry component is refers to the packaging industry in a close contact with the industry commonly used functions. Using GPS for monitoring as an example. For GPS applications, in addition to the map display information inquiry and so" on the general function of GIS, but also need to specific application functions

As shown on the dynamic target, target, track and display. The GPS industry application of functional components are encapsulated, developers can simplify set to display the target of legend, trajectory display color, lock the target, and call, receive data method.

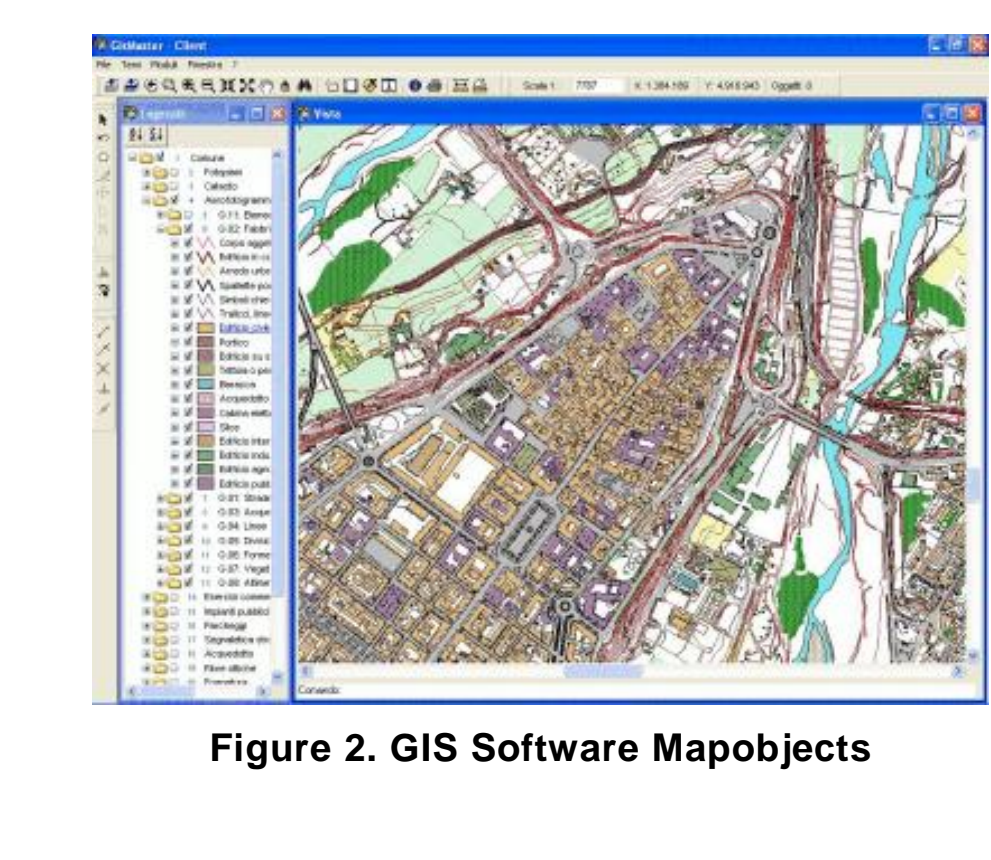

\subsection{The Integration of GIS and MIS}

MIS (ManagementInformationSystems) first appeared in the last century in 70s, it is a use of computer hardware and software, manual work, analysis, planning, control and decision-making model. After years of development, the management information system of environment, goal, function, support level, which has the connotation is a great change ofMiS a continuous development of new disciplines, the definition of MIS with the development of computer technology and communication technology advances are constantly updated, at present it is generally believed that MIS composed by human and computer equipment or other information processing method and system for managing information. From the view of technology, management information system is the enterprise organization management in order to solve various problems faced by an integrated computer hardware and software tools. In the management information system, including computer technology Hardware technology, software technology, communication and network technology, Internet technology, database technology. MIS features include: 
- The object of the management information system is the information

- Management information is composed of five parts: information collection, information transmission, information storage, information processing, information maintenance and information usage.

- Sound management information system has the following four standards: to determine the information needs, information can be collected and processed, you can provide information for the management of personnel, the information can be managed

- The database with unified planning is an important symbol of the maturity of the management information system, which symbolizes that MIS is the product of software engineering.

- Management information system is the development of change, management information system has the life cycle

- Management information system is a comprehensive interdisciplinary subject

Because the lack of MIS management of spatial information, we not to mention on the spatial analysis. Using GIS spatial information management and analysis funct on, the sublimation of ordinary MIS GMIS system with visual information, management range, angle were information management and analysis and decision-making provides a convenient. Can the map information in an image, inturive convenient entry, query, statistics and other operations and with the help of GIS spatial analysis function, the necessary analysis, greatly enhancing the practicality of the MIS.

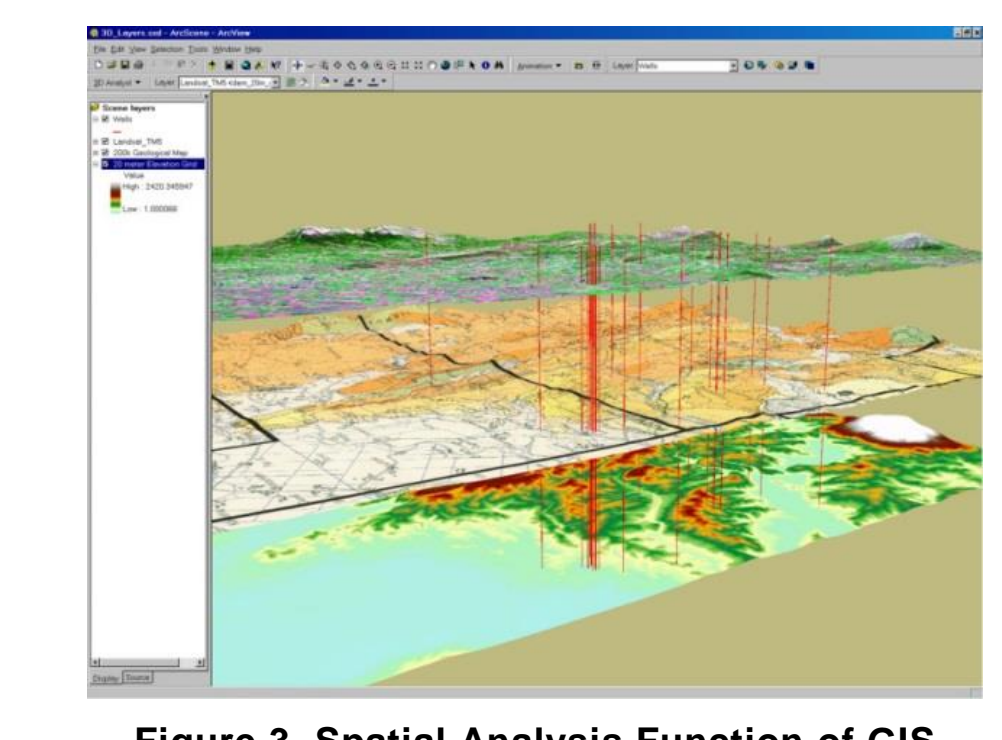

\section{0 \\ Figure 3. Spatial Analysis Function of GIS \\ 3. Civil Air Defense Engineering Management Information System based on GIS}

\subsection{Realization of the Main Interface of the System}

The establishment of VISua1C\# project in visualStudio.NET, to add references to MO components to use the component. Open the Add Reference dialog box project, select the $\mathrm{COM}$ tab in the options page, search and select ESRIMapobjeets2.3, and then click the list box on the right side of the Select Selected Components button to add components to the list box, click OK to close the dialog box to complete the add reference. After the completion of the assembly references, the application can use the M0 components, but still can not use the M0 map control by adding to the main form project. To achieve this, 
first open the project the Toolbox window, right click in the toolbox, select from the popup menu custom toolbox 0 command, open a custom dialog box. Select the $\mathrm{M}$ toolbox of the check box before the Control option, click OK button will be added to the map control toolbox.

The main function of the system is realized through the main form, so the main form is mainly composed of the following parts.

1) Status bar: In the form of added statusbar control, named for the statusbar. In the properties window for the control of the selected control panels property, open the status bar panel tool Editor dialog box, in the dialog box increased four panel, named for_statusBarPane11,_statusBarPane12, _statusBarPane13, _statusBarPane14, four panel in the status bar respectively for display system name, the latitude and longitude to the point where the mouse, the map of the current type of operation as well as the current map display scale and other information.

2) Toolbar: In the form of add toolbar controls Too1Bar control named for the toolbar, the toolbar to the dock property is set to top the toolbar is placed to form the top. And in the toolbar add zoom in, zoom, roaming, map display, click engineering tool buttons and the corresponding image tool.

3) Panel: In the form of adding multiple panel controls, for the realization of Engineering query set, map control, display map legend, and engineering analysis etc. function.

CEnvironment is system function mainly implementation class, most of the functionality of the system are in such complete "for the Cystem to achieve the main function, the first in the CEnvironment class file design has some helper classes and auxiliary structure, then according to the detailed design of the Tim and initializes the class variables" MaPInfo structure for storing the map information, including the names of maps. Map data metadata table name, map type, map outsourcing rectangular information ".

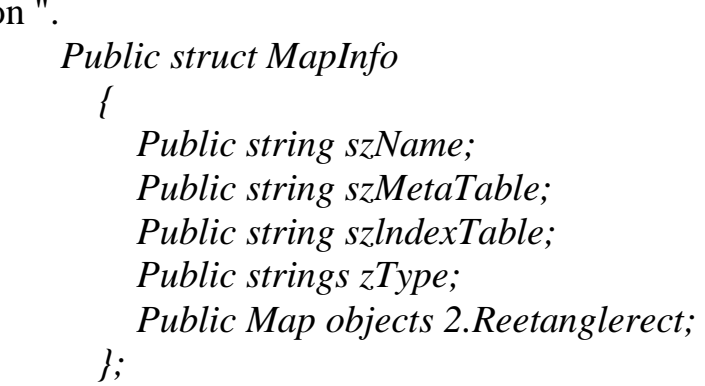

\subsection{Oracle Relational Database Management Technology}

System a large number of attributes information using Oracle relational database management technology management. Including civil air defense project information, system management information and layer management information, etc.. Oracle support large dalabases and multi-user high-performance transaction processing, with portability, compatibility and connectivity, Oracle developed applications can be ported to any operating system, and allows different types of computers and operating systems to share information through the network. Good safety performance, support for Internet applications, advanced performance. According to the system requirements, design the layer information table, engineering survey information table and other data tables, as shown in Table 2, Table 1. 
Table 1. The Layer Information

\begin{tabular}{|c|c|c|c|}
\hline Serial & Name & data type & Size \\
\hline 1 & $\begin{array}{l}\text { Layer } \\
\text { number }\end{array}$ & $\begin{array}{l}\text { VARCHAR } \\
2\end{array}$ & 10 \\
\hline 2 & layer name & $\begin{array}{l}\text { VARCHAR } \\
2\end{array}$ & 50 \\
\hline 3 & $\begin{array}{l}\text { ground } \\
\text { object field }\end{array}$ & $\begin{array}{l}\text { NVARCHA } \\
\text { R2 }\end{array}$ & 10 \\
\hline 4 & feature type & NUMBER & 20 \\
\hline 5 & $\begin{array}{l}\text { display } \\
\text { order }\end{array}$ & NUMBER & 20 \\
\hline 6 & $\begin{array}{l}\text { display } \\
\text { symbol type }\end{array}$ & NUMBER & 20 \\
\hline 7 & $\begin{array}{l}\text { display } \\
\text { symbol color }\end{array}$ & NUMBER & \\
\hline 8 & $\begin{array}{l}\text { display } \\
\text { symbol size }\end{array}$ & & 20 \\
\hline 9 & layer type & & 20 \\
\hline 10 & $\begin{array}{l}\text { graphics file } \\
\text { name }\end{array}$ & & 30 \\
\hline 11 & attribute & VARCHAR & 30 \\
\hline 12 & file name & עARCHAR & 30 \\
\hline 13 & & $\begin{array}{l}\text { VARCHAR } \\
2\end{array}$ & 10 \\
\hline 14 & & $\begin{array}{l}\text { VARCHAR } \\
2\end{array}$ & 10 \\
\hline 15 & & $\begin{array}{l}\text { VARCHAR } \\
2 \\
\end{array}$ & 10 \\
\hline & & NUMBER & 20 \\
\hline 17 & note scale & NUMBER & 20 \\
\hline 18 & can choose & NUMBER & 10 \\
\hline
\end{tabular}

Table 2. The General Project Information

\begin{tabular}{|c|c|c|c|}
\hline Seri & Name & data type & Size \\
\hline 1 & project number & NUMBER & 10 \\
\hline 2 & docket No. & NUMBER & 20 \\
\hline 3 & region name & $\begin{array}{l}\text { VARCHAR } \\
2\end{array}$ & 50 \\
\hline 4 & project name & $\begin{array}{l}\text { VARCHAR } \\
2\end{array}$ & 100 \\
\hline 5 & engineering site & $\begin{array}{l}\text { VARCHAR } \\
2\end{array}$ & 200 \\
\hline 6 & wartime use & NUMBER & 3 \\
\hline 7 & peacetime use & NUMBER & 3 \\
\hline 8 & construction area & NUMBER & 20 \\
\hline 9 & e area & NUMBER & 20 \\
\hline
\end{tabular}




\begin{tabular}{|c|c|c|c|}
\hline 10 & protection class & NUMBER & 3 \\
\hline 11 & masking personnel & NUMBER & 20 \\
\hline 12 & storage volume & NUMBER & 20 \\
\hline 13 & entrances and exits & NUMBER & 20 \\
\hline 14 & $\begin{array}{c}\text { maintenance } \\
\text { management }\end{array}$ & NUMBER & 3 \\
\hline 15 & engineering type & NUMBER & 3 \\
\hline
\end{tabular}

\subsection{Map Display}

ADO.NET is a set of libraries that are included in the.NET framework for communication between various data storage in the .NET application. ADO. Net library contains and data source connection, query and processing results, also can be ado. Net as a strong, hierarchical, broken open connection to the data cache to use, the offline data processing. The most important disconnected object data set can be performed to sort, search, filter, store, suspend, change, and then browse the data in hierarchical data. Data set also contains a lot of other functions, to fill the gap between traditional data access and XML development. .NET contains the ADO.NET data provider that is used to connect to the database, to execute commands, and to retrieve the results. Can deal directly with the retrieved results, or place an ADO. Net dataset object, to and from multiple data sources of data or between the layers for remoting data are combined together in a special way to users open. ADO.NET Data-Set objects can also be used independently from the.NET data provider to manage the application's native dat or from the XML data. OracleClient.NET data provider is the Microsolt dedicated to the development of Oracle database.NET data provider. This program ean communicate with the $8 \mathrm{i}$ version of the Oracle database and later versions of 81 , and supports aceess to updated Oracle data types, such as LOB and BFILE, etc. Orachelient.NET data provider using the Oracle client library and Oracle database communications. Among them, the class Oracle Connection is used to connect the Oracle database, Oracle Data Adapter is used to obtain the results of the query, and the results can be obtained through the Fill function to fill the data set.

The system is through the Map tab in the "layer" control panel to achieve humancomputer interaction control map display. Join tree list layer control panel in the "map" tab on the (Tree Kiew), add on behalf of each layer of the nodes in the tree list, as shown in Figure 4 "check box before node for display control layer when the check node represents the node layer will be displayed, otherwise the node represents the layer does not display" check with the mouse to click on the box in front of the tree list node, change the state of the check box, the on Tree view Item checked function trigger system, according to the layer control tree list control options to control objects the type of "display in the map.

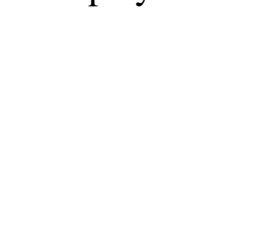




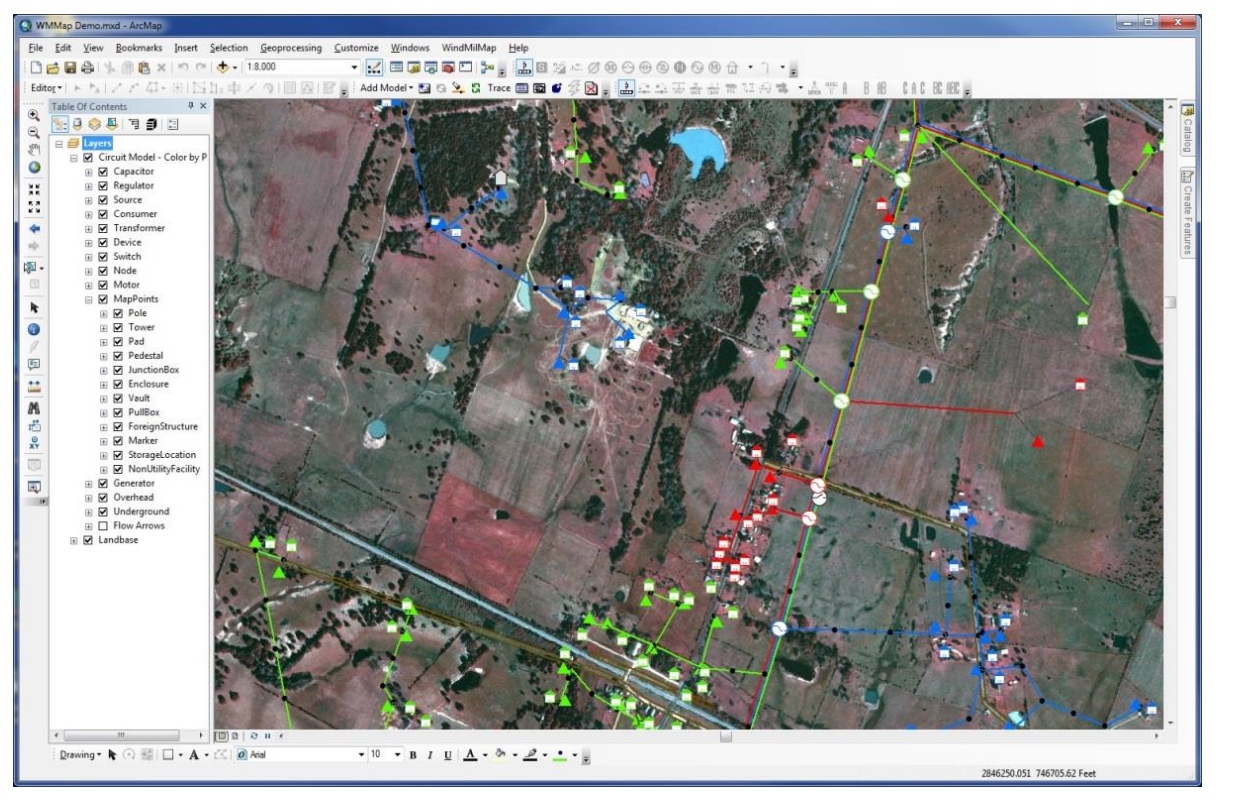

Figure 4. Map Options

Map zoom, map display and roaming is the most basic functions of electronic map. In Mo is mainly realized through the map control extent attribute extent is an attribute of type rectangle, it said current map display range, $m$ controlos he other a property Fully Extent said coordinates of all layers of the total range of values".

(1)The realization of map enlargement

In Mo map zoom function is very simple to acheve, to pull frame to enlarge the realization, for example, just the nap control Track Rectangle method of drawing out the rectangular region assigned to map controls the current display range can be "example code for:

_Map. Extent=_Map. TrackReetangle N:

(2) The realization of map reduction

Zoom out of a map function to achieve a little bit more complicated, first of all to contract the settings of multiple, in Mo map reduce is equivalent to the current map display range zoom "will be-the realization of the map reduce to 2 / 3 of the original code is as follow:

Rect $=\_$MaP.Extent .

Reet.ScaleRectangle (1.5);

This._Map.Extent=reet:

(3) The realization of map display

Diagram shows the amplification with map implementation is somewhat similar, the difference is only need to map control of all layers of the total range of coordinate (FullExtent attributes) assignment to the current map display range (extent) can be, the code that is:

MaP.Extent $=\_$MaP.FullExtent

\section{Conclusions}

With the development of database technology and component technology, the integration of MIS and GIS has become more and more mature. MIS and GIS Integration in the powerful information management capacity of MIS based on combines the GIS spatial data management and spatial analysis ability, in GIS image, intuitive map visualization interface up to manage the complexity of the information and data, and provide the spatial analysis and decision support etc., has a broad application prospect. 
Integration of GIS and MIS greatly improves the performance of MIS, will greatly promote the development of MIS. This system adopts MIS integrated technology of GIS and the successful implementation of the function of the management information system of civil air defense engineering, on the basis of also implements the analysis functions of the civil air defense engineering information management needs, the system is simple and practical, powerful, after the completion of the system into civil air defense, to achieve the desired effect good.

\section{Acknowledgements}

This research is supported by City Construction Department, Shaoyang University Research Project <Optimization Study on Single Building Defence Engineering Construction> (14C1016).

\section{References}

[1] M. Le-Wei, Z. Xiao-Jun and X. Yi-Tong, "Dynamic Characteristics Analysis Method of The earthquake waves on The basis of Matlab language", Journal of Shaanxi University of Science \& Technology, vol. 27, (2009), pp.130-134.

[2] C. Jie, "The Research of Earthquake Ground Motion Input in High-level Structure Adjustment Based on Wavelet", Xi'an: Xi'an University of Architecture and Technology, (2013).

[3] S. Mukherjee and V. Gupta, "Wavelet-based generation of spectrum-compatible time-listories", Soil Dy- namics and Earthquake Engineering, vol.22, (2002), pp.799- 804.

[4] L.Suarez and L .Montejo, "Generation of artificial earthquakes via the wayelet transform", Journal of Solids and Structures, vol.42, (2005), pp.5905-5910

[5] Z. Changhao, "Simulate the Seismic Wave and Analysis Dynamic Response of Engineering Structures", Xi' an: Chang'an University, (2012).

[6] Z. Zuozhou and H.U,Q. Jiaru, "Comparison of ground motion selection between Chinese and American methods and elasto-plastic time histor analysis of frame-core wall structures", Journal of Building Structures, vol.36, (2015),pp.10-18.

[7] M. Qianli, Y. Lieping and L. Xinzheng, "Study on lateral load patterns of pushover analysis using incremental ynamical analysis for RC frame structures", Journal of Building Structures, vol.2, (2008), pp.132-140.

[8] C. Jinfeng,W. Xuchun and R, Liang, "The Python language application in Abaqus", Beijing:Mechanical industry press, (2011)

[9] L.Xuchuan,L.Xinzheng.M.Zhiwei, "Finite element analysis and engineering application of RC core-tube tructures based on the multi-layer shell elements", China Civil Engineering Journal, vol.3, (2009), pp.49-54.

[10] Z. Ming Huang, "Inelastic and failure analysis of laminate structure by ABAQUS incorporated with a general constitutive relationship", Journal of Reinforced Plastics and Composites, vol.26, (2007), pp.1135-1181.

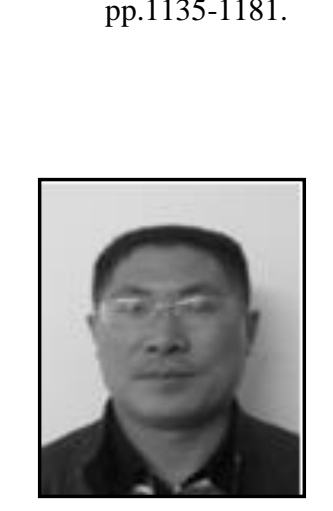

\section{Author}

Lin Zhang-Yin> <1973.07 Shaoyang, Hunan,P.R.China>

Current position, grades: Urban Construction Department of Shaoyang University, Hunan Province

Scientific Interest: His research direction is the architectural engineering project construction and management

Publications: more than 8 papers published

Experience: He has teaching experience of 14 years, has completed two scientific research projects 